$(200)$
$R 290$

20.1329

UNITED STATES DEPARTMEM OF THE INTERIOR GEOLOGICAL SURVEY

Maps showing locations of holes drilled in 1955

by U.S. Geological Survey, Clay Gulch area,

San Juan County, Utah

of fe 69-302

Open-file report

1969

This report is preliminary and has not teen edited or reviewed for conformity with U.S. Geological Survey standards. 


\section{$\therefore$ Kaps showing locations of holè drilled in 1955 \\ by U.S. Geological Survey, Clay Gulch area, San Juan County, Utah}

Between October 19, 1955, and November 26, 1955, the U.S. Ceological Survey drilled 9 holes in Clay Gulch area, San Juan County, Utab, to obtain geologic information that could be used in exploring for uraniunbearing deposits in the Shinarump Kember of the Upper Triassic Chinle Pormation.

The accompanying maps of the area explored are an index map (fig. I) and another showing locattons of holes drilled (fig. 2). Logs of boles Identified on the location map may be inspected at the U.S. Geological Survey Library, Building 25, Federal Center, Denver, Colo. 80225, and at the U.S. Atomic Energy Comission office, Grand Junction; Colo.-81501. 


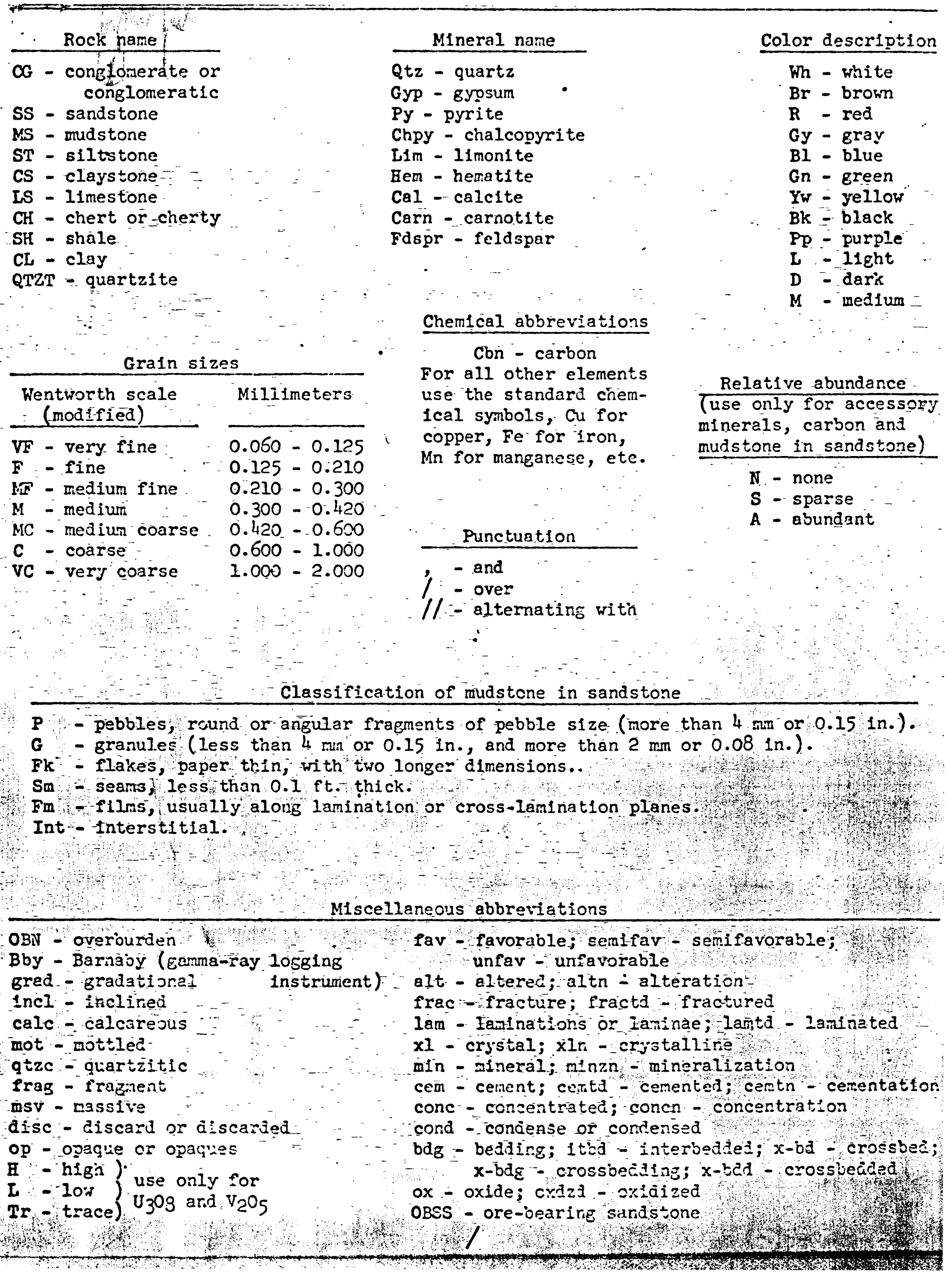


ABBREVIATIONS FOR GEOLOCIC AID ASSAY IOGS--COntinued

$\vdots \therefore \quad \therefore$

$\because \because \because{ }^{\circ}$

ation. in

Symbols for stratigrachic units

Fal = Chinle jormation, lower nart

Fs - -Shinerung nember of Cininle formation

Fm - Loenco iormation

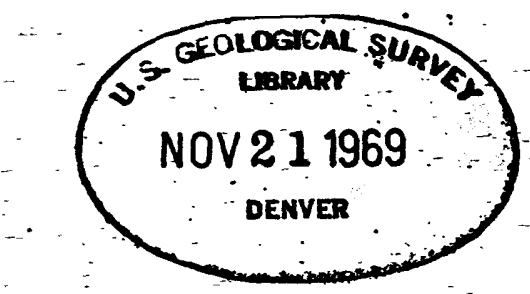




\section{Additional Information About Logs}

The additional information contalined in this supplement is useful in interpreting the GEOLOGIC AND ASSAY LOGS form.

Collar elevation.--Generally this is the elevation above mean-sea level of the drill-hole collar. The elevation in the space before $T$ is temporary, that in the space before $P$ is permanent. Permanent elevations are determined by plane-table methods; temporary elevaitons are determined by less accurate means.

Sumary of $\log$--Each of the terms "favorable, "semffavorable," or "unfevorable" sums up the geologic factor's that determine whether or not the hole is in ground considered favorable for the presence of ore. For instance, the terin "favorable" irdicates that the hole is in ground that shows most of the criteria that are present near ore deposits. A "favorable" hole is not necessarily. one that is in mineralized rock.

Core recovery,--This is noted only where it is less than 80 percent. Poor recovery may mean that the log presents an incomplete geologic record of the unit of low recovery.

Field estirate - The column headed "U308" gives the uranlum oxide values based on visual estímates and portable geiger-counter readings made by the fleld geologist. The column headed " $\mathrm{V}_{2} \mathrm{O}_{5}$ ". gives vankdium oxide -valies based on visual estimates made by the field geologist.

Assays.--The values given in the columns headed "lab assay ( $\phi)$ " are chemical assays, with the exception of those preceded by "e." Chemical assays for uranium are determined only for those samples that register 0.045 percent or more $\mathrm{eU}_{3} \mathrm{O}_{8}$. Values preceded by "e" are determined by a laboratory gamma-ray scanner; they represent-equivalent $\mathrm{U}_{3} \mathrm{O}_{8}$ values of rock samples sent. in from the field. Gamma-ray values determined in the laboratory are generally more accurate than field estimates.

In the column headed " $/$-ray, feu 308 ," the values given are determined from a gamm-zay field log, obtained by logging the arill hole with a gelger-counter probe. Gama-ray values are given only for samples that register 0.010 percent or more $\mathrm{U}_{3} \mathrm{O} 8$.

Where notation about gamma-ray logging is lacking it is assumed that the hole was not logged raciometrically.

$\mathcal{Z}$-ray log.--This coliumn may be disregarded. See $\mathscr{V}($ gama)-ray sub-column on lower part of loz sheet.

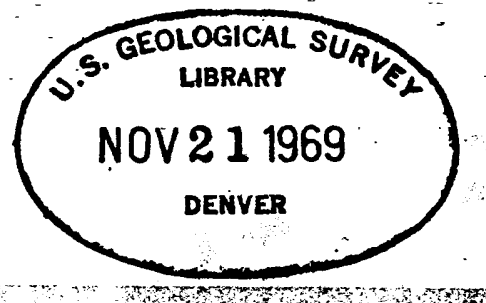


증

13 -

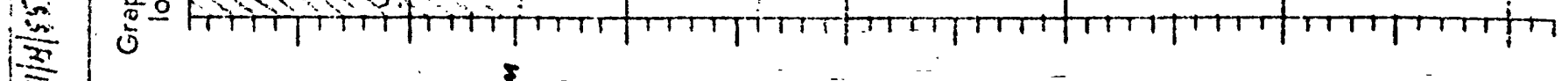

$-3$

(Sitis

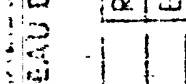

尔

,

.

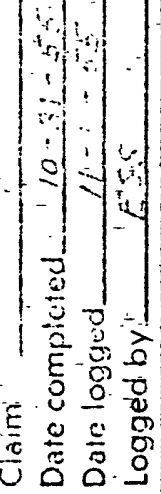

$\mid$

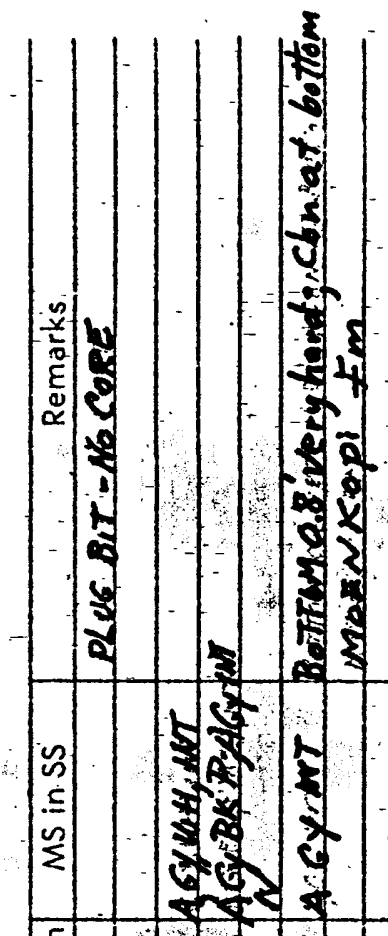

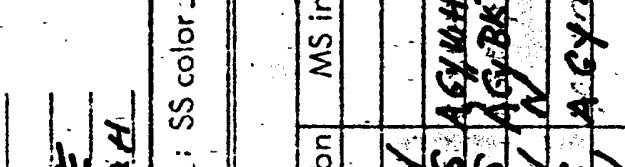

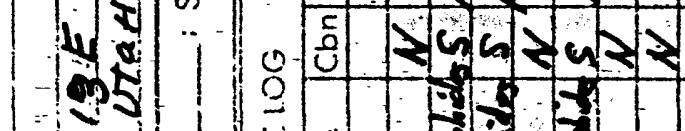

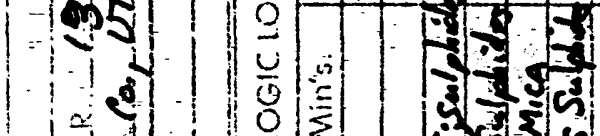

120010

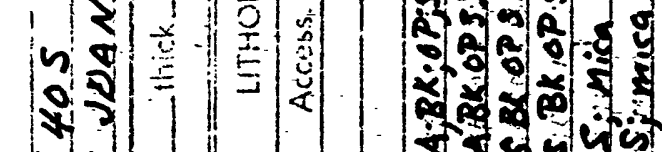

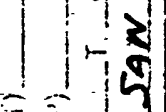

$\because \infty$

$\because \infty \| \frac{0}{1}$

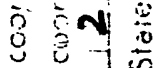

ले

Fis isis

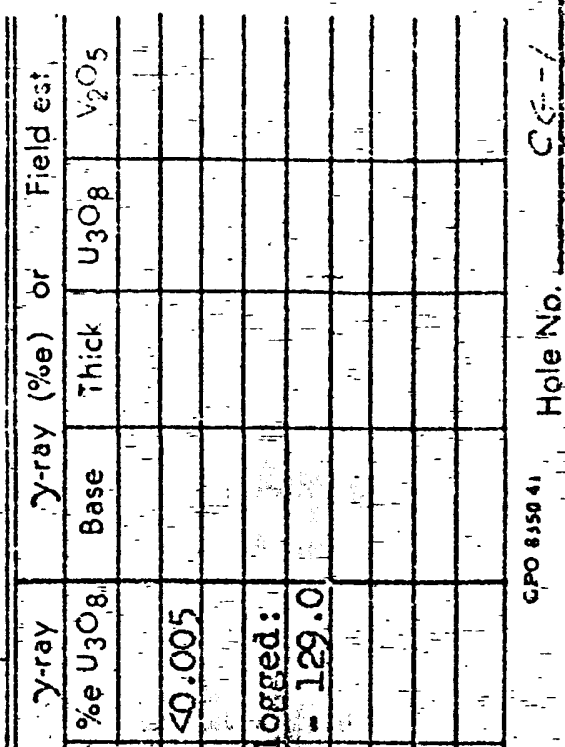

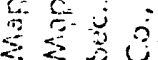

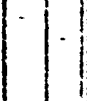

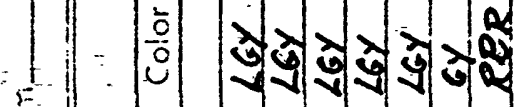

.

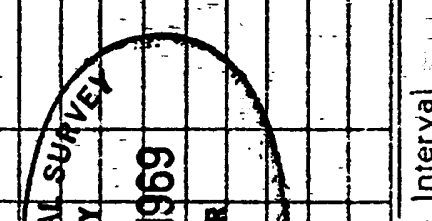

药

os

ㄴ.

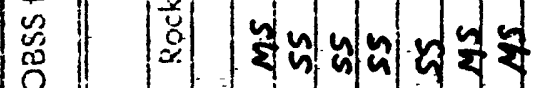

$\frac{2}{2}$ w

()

家

0

$\log$

mon

qoolommso :

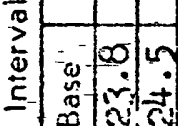

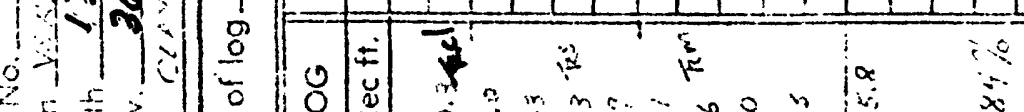

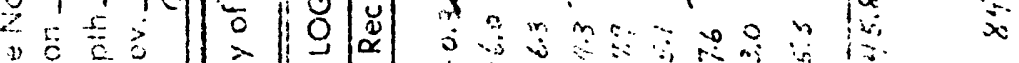

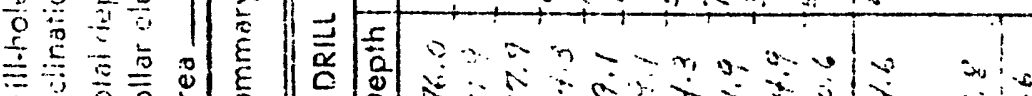

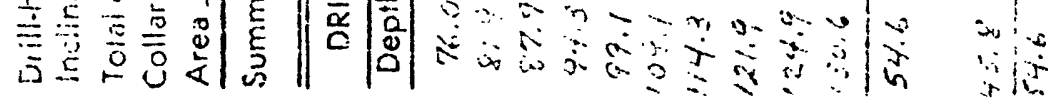




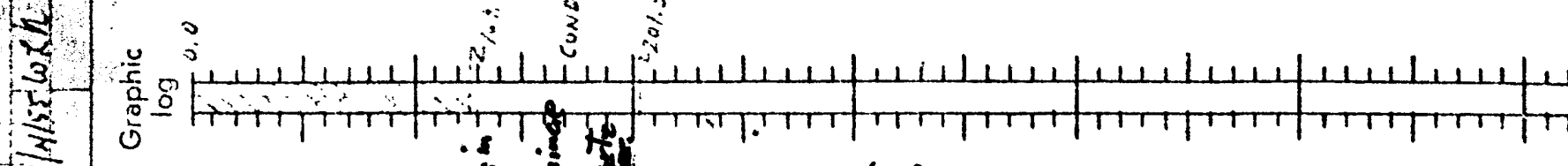

$\because \frac{x}{x-15}$

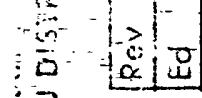

$\because 2$

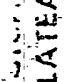

30

0

8

in $1: 10$

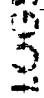

$-\left|\begin{array}{l}4 y \\ m\end{array}\right|$

$=\sqrt[3]{1} \cdot 10 x$

$\frac{0}{0}$

造 0

-

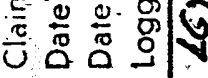

$-m$

$\forall$

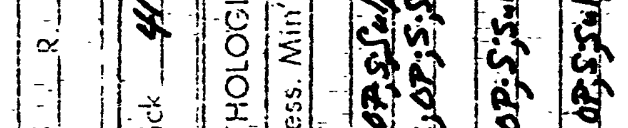

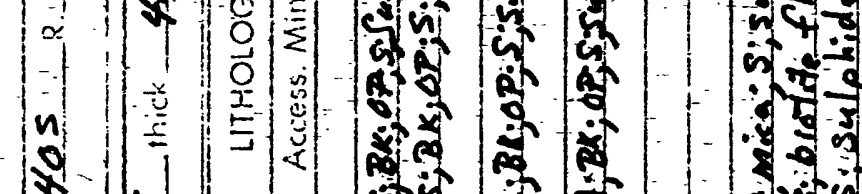

$\because-1 w$

$=15 \div$

$\bar{\Xi}=\infty$

$800 \frac{0}{8}$

点造:

$\sum \sum$ i 0

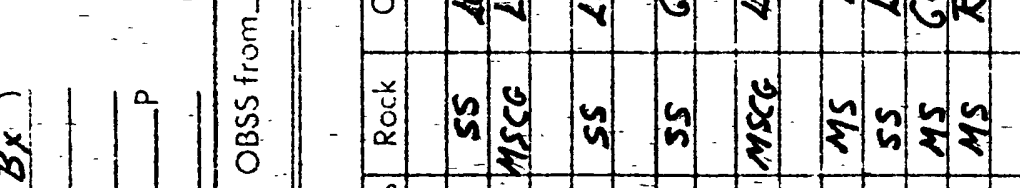

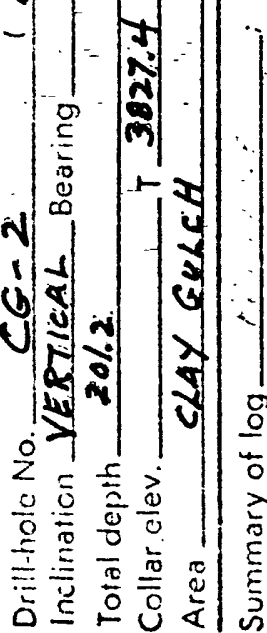

낭

$\alpha \times 2$. * 1 on 0 y

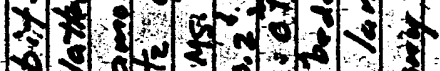
405 \& 3 전

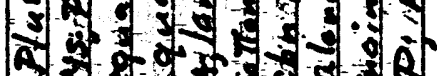

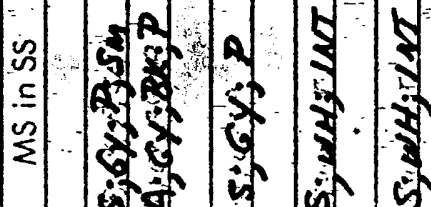

들

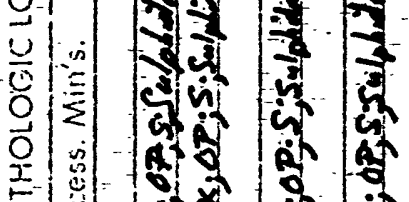

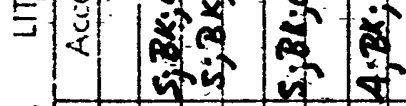

$\frac{5}{0}$ 궁

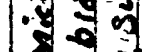

12.

\begin{tabular}{|c|c|c|}
\hline 0 \\
0 \\
$-u$ \\
$\alpha$
\end{tabular}

Fy

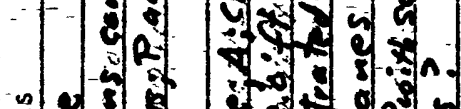

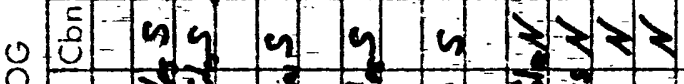

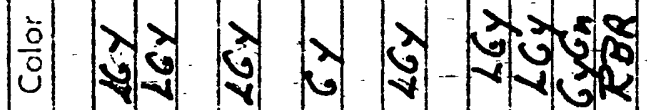

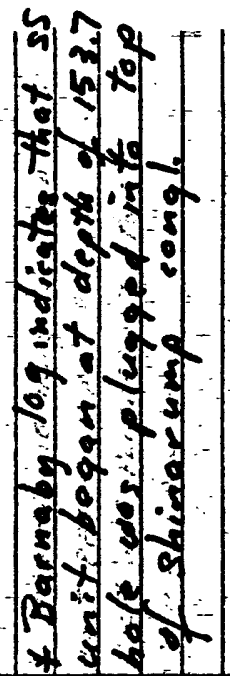

incis

s.

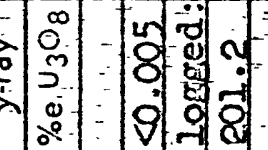

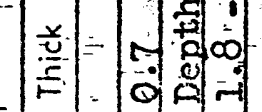

$2 \frac{0}{9}$

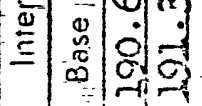
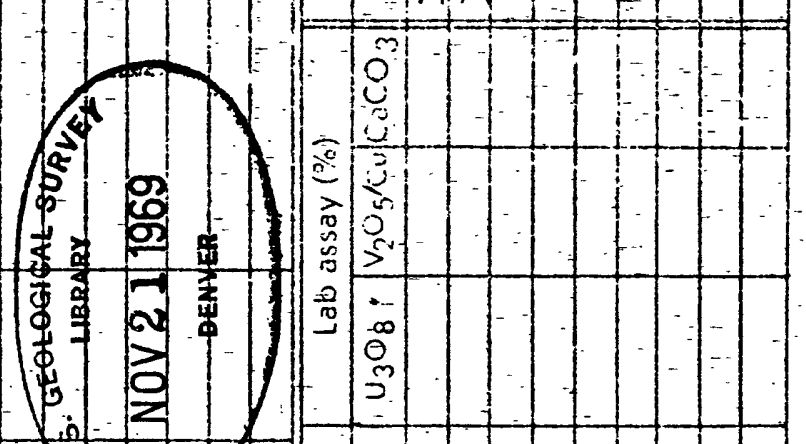

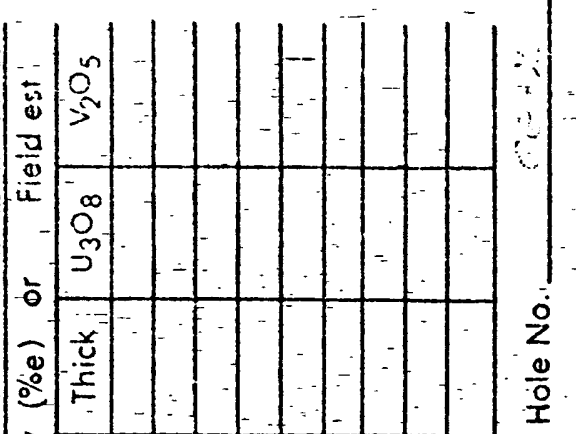

ते

$\mid \begin{aligned} & = \\ & 0 \\ & 0 \\ & 0 \\ & 0 \\ & 0 \\ & 0 \\ & 0\end{aligned}$ 


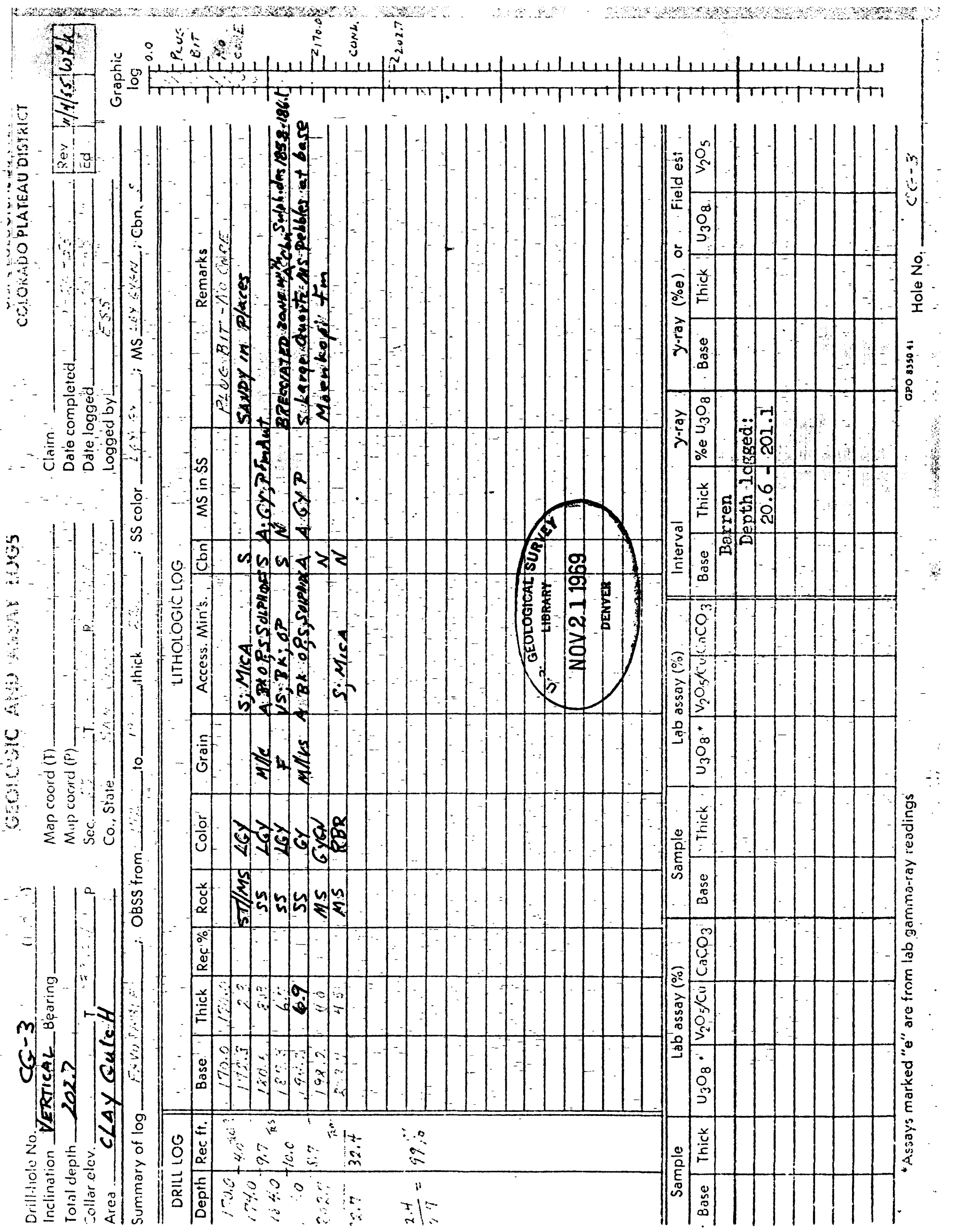




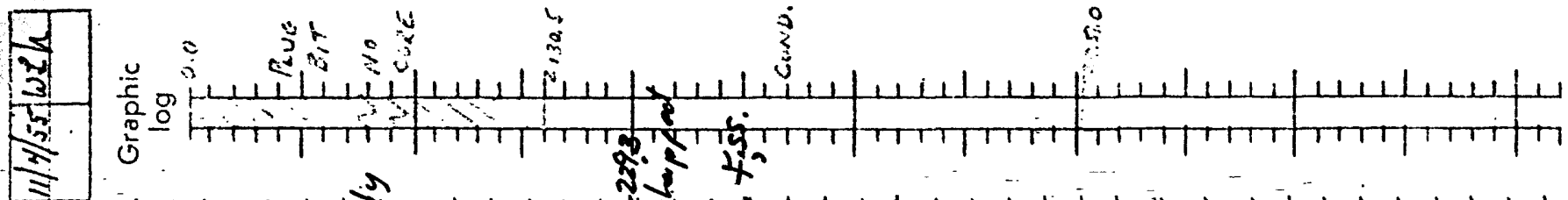
$=$

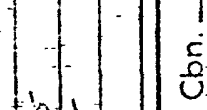

if?

$\begin{array}{ccc}1 & 0 \\ 1 & m_{3} & 0\end{array}$

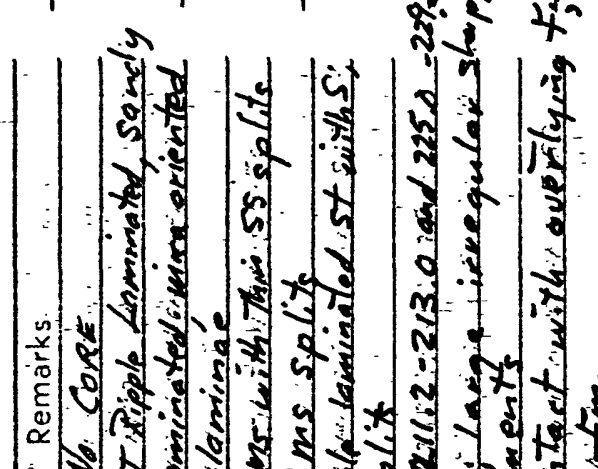

为

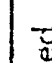

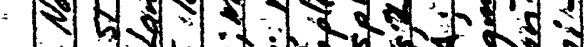

$\sum$

可

8 - 0 |1

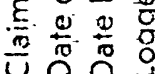

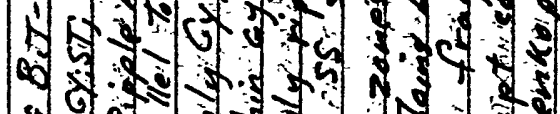

จ क्री
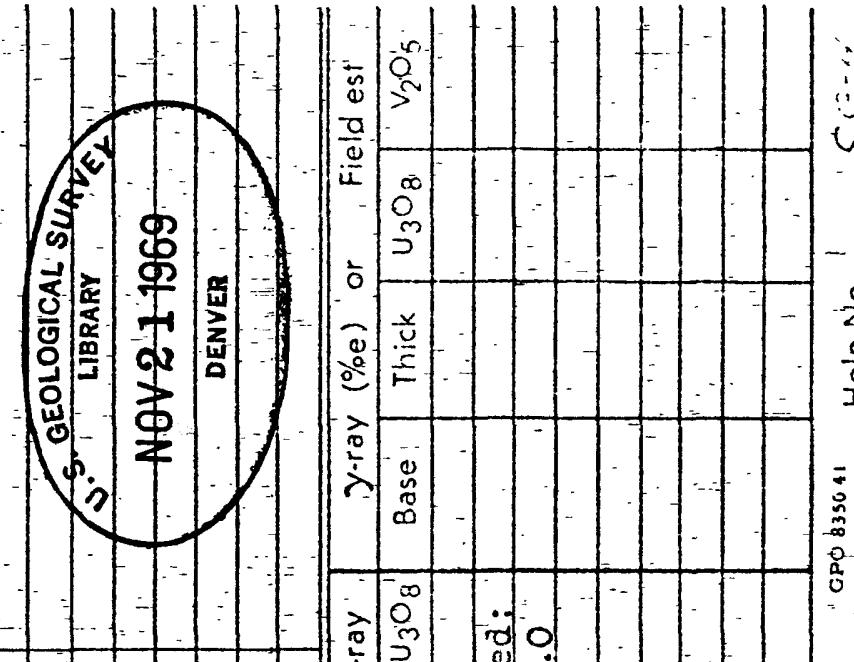

인 立

1

4

m.

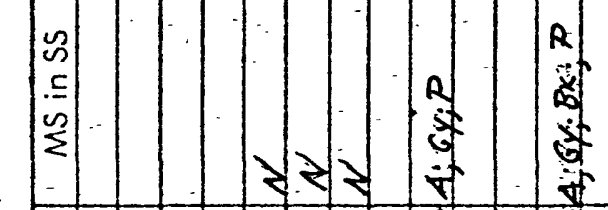

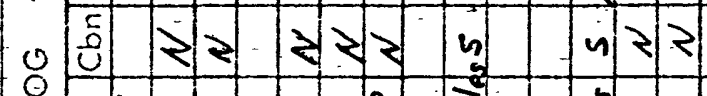

$4\left(\begin{array}{lll}0 \\ 0 \\ 0 \\ 0\end{array}\right.$

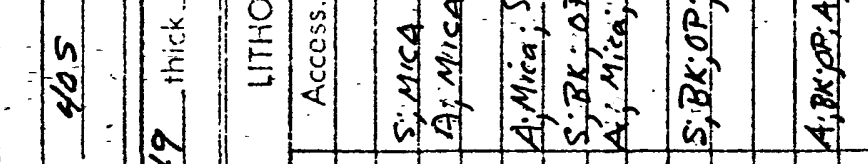

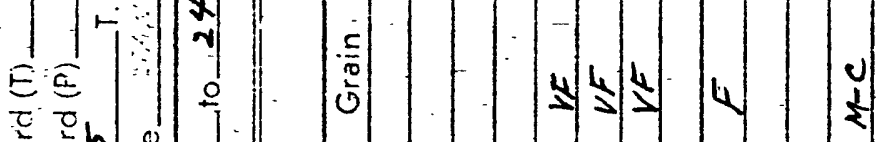

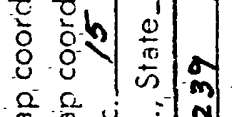

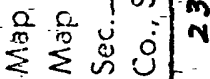

E

$=1|1| \begin{array}{lll}a \\ n \\ 0 \\ 0\end{array}$

.

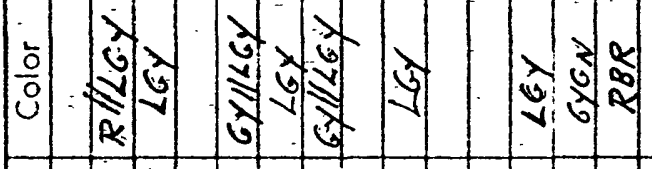

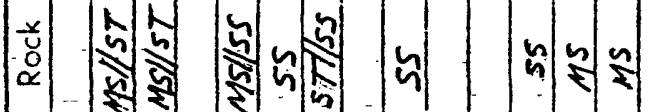

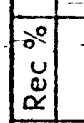

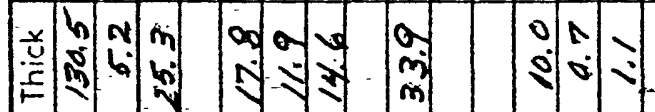

1
$y$
$y$
$y$
$y$

con

영용

果

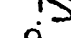

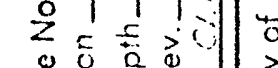

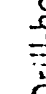

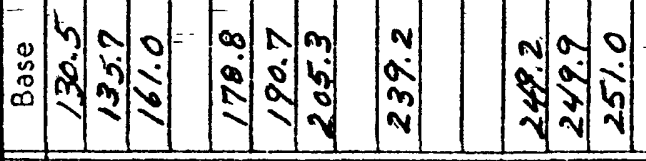

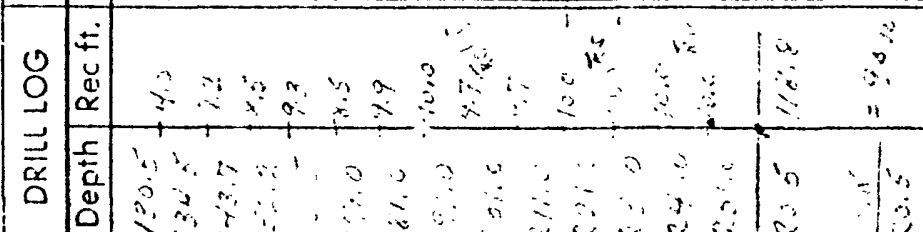

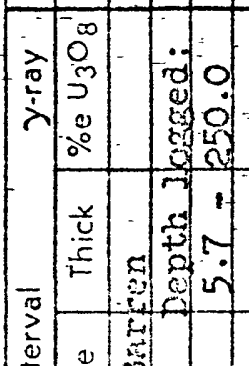

-

a.

خे

خับ

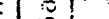

$\frac{3}{3}$

文

兵 *

$\infty$
-
$-\infty$
$\infty$ 


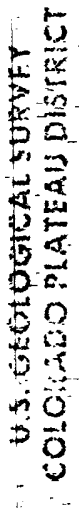

(1)

12.

$\pi$

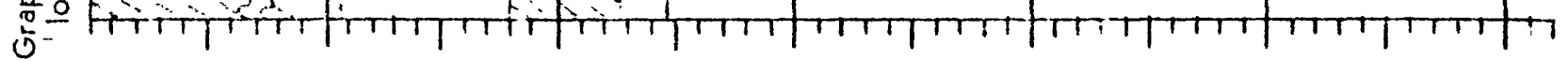
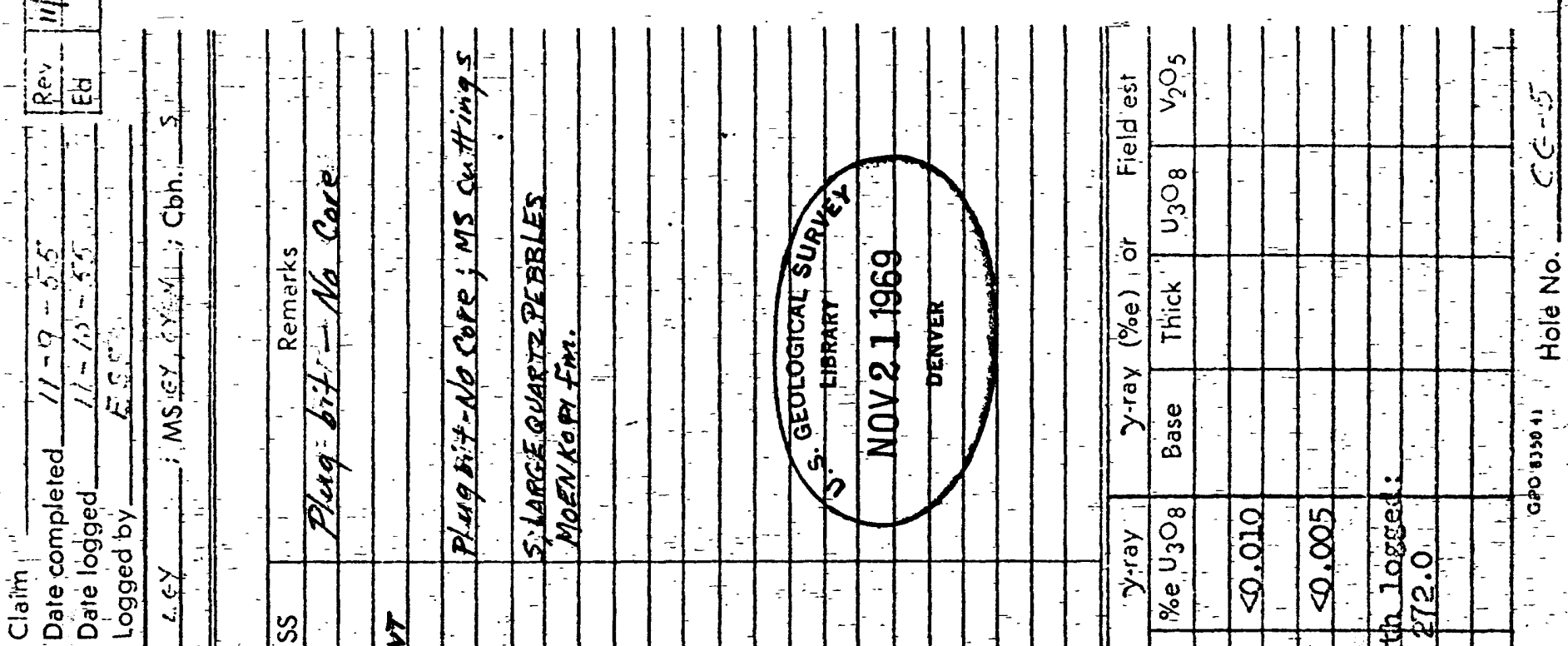

8

的

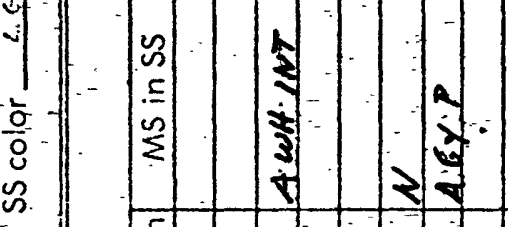

0.023 in $3 \geq>$

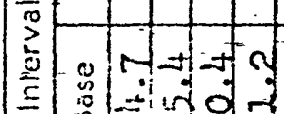

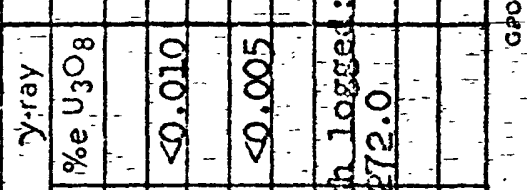

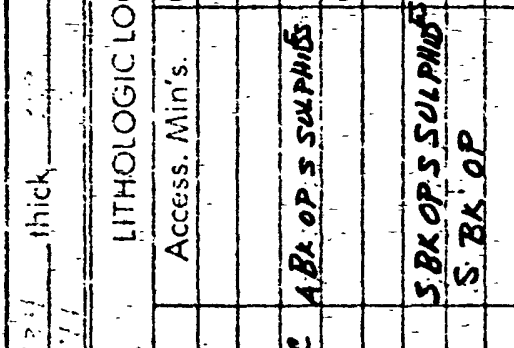

10

$\alpha$

E $\frac{2}{2}(1) \mid 0$

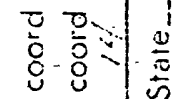

ज.

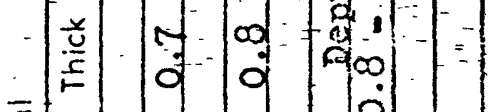

齐

을 $\frac{\pi}{\pi}$

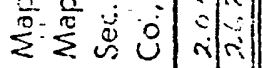

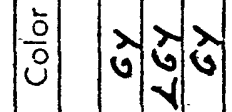

$E$
0
2
足
0
0
0

苟

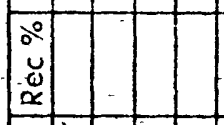

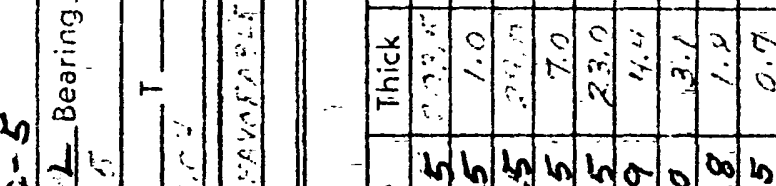

Wh h n lno 00 m

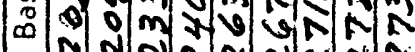

$=$ ind

(b)

Biv

些 >

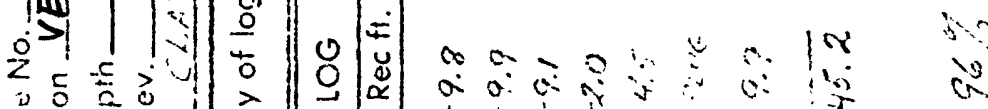

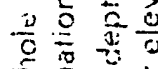

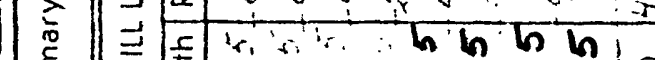

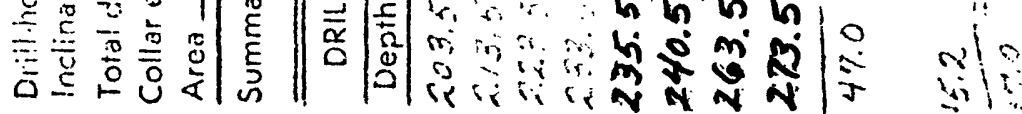

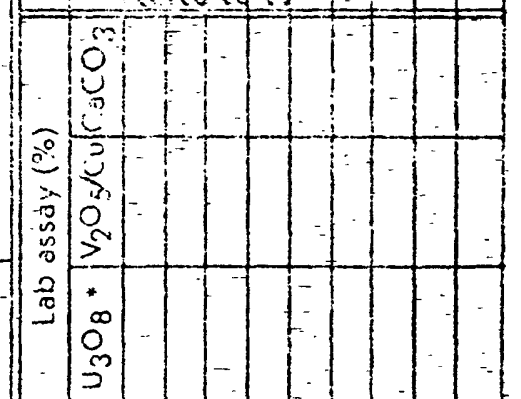




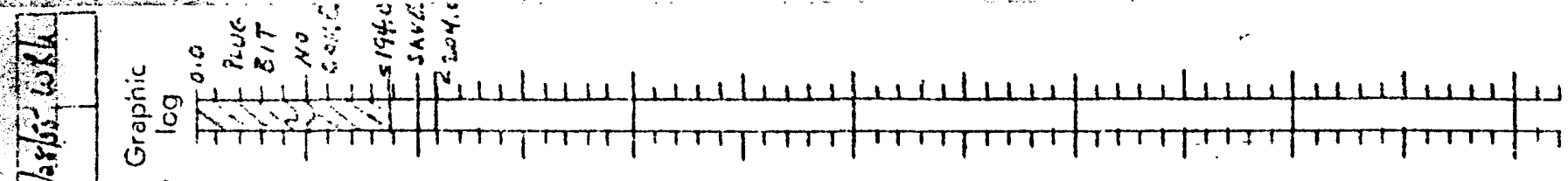

政

:

i:

:

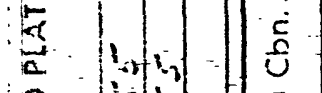

9

m

.

3
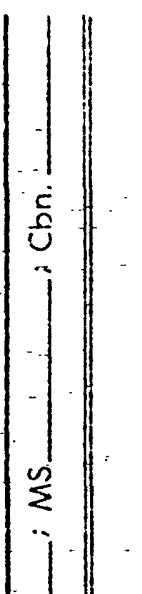

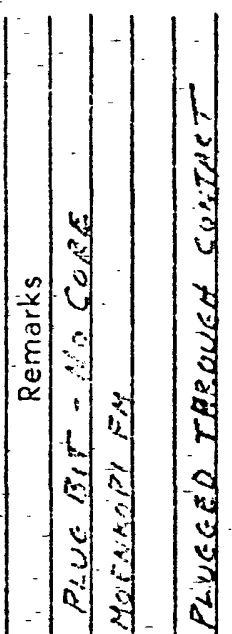

每

응응

E $\frac{E}{10} \frac{\omega}{0}$
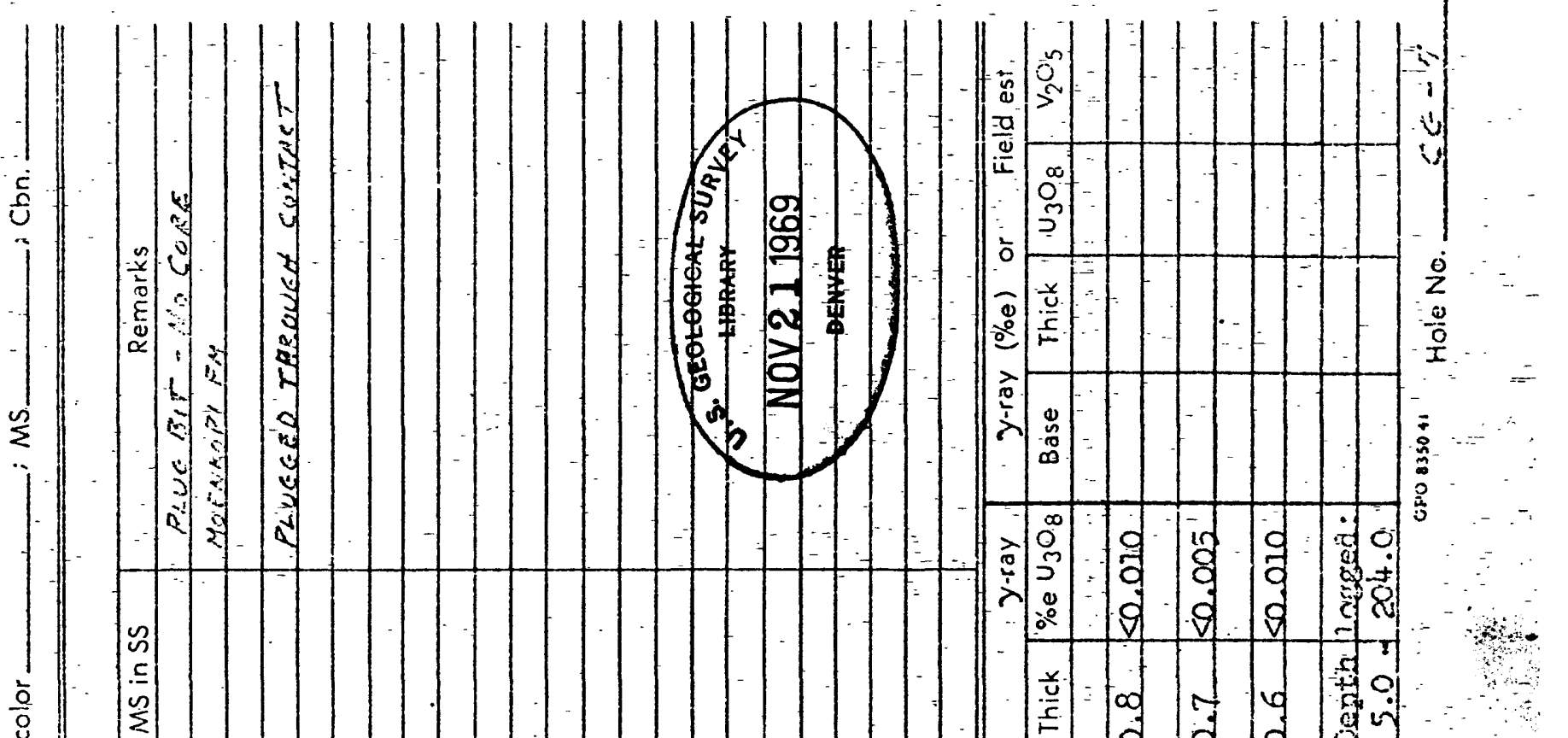

$11 \mid \begin{aligned} & 0 \\ & \text { un }\end{aligned}$

,

\begin{tabular}{|l|l|l|l|l|l|l|}
\hline 0 & & \\
0 & 0 & \\
\hline
\end{tabular}

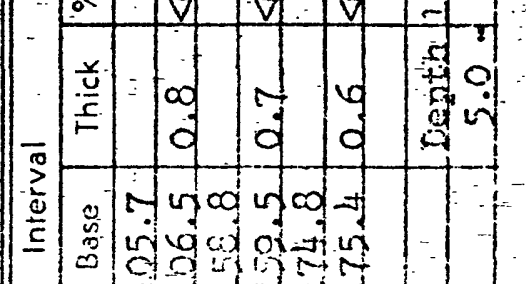

18

0

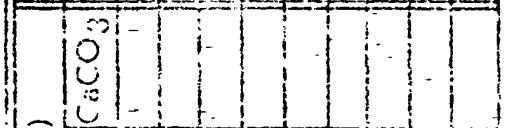

$-8$

1.

1.4

100

$15-2$

$\frac{1}{2}-4$

$\int_{0}$

$\because \overline{2}-10$

$\frac{5}{5}$

年

하 \&

政

$\sum^{0}=0$

-

ह. - y

妾

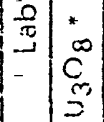

$=\because \quad=1=0$

至

$1 \quad a_{x}$

\begin{tabular}{l}
0 \\
\hdashline \\
0
\end{tabular}

a

$\because 1.10$

(4) 6 a

म $35=$

4.

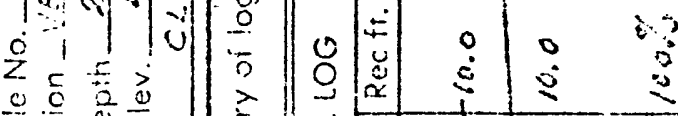

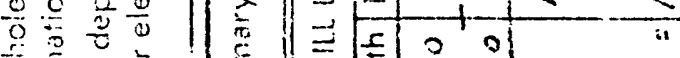

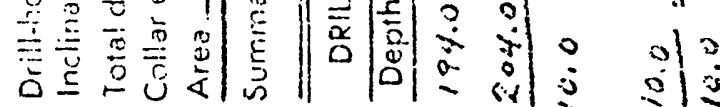

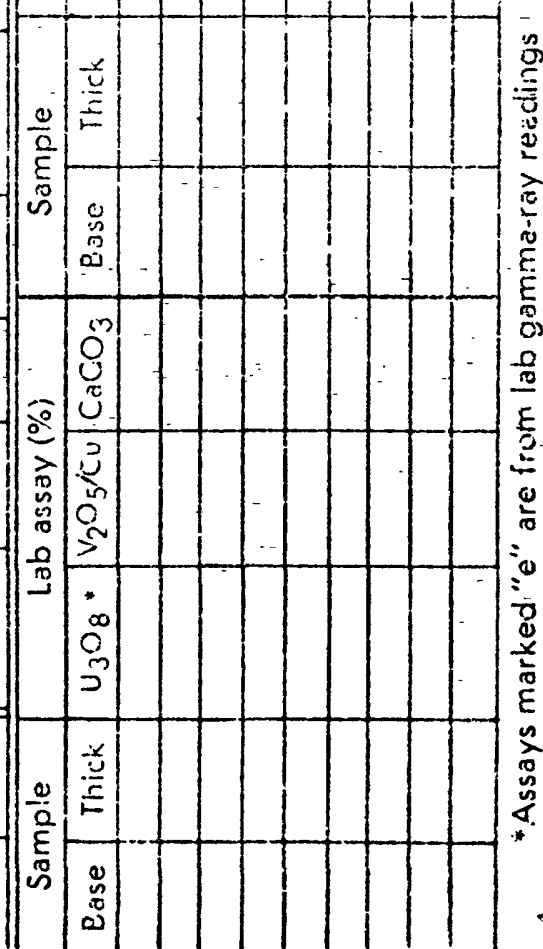




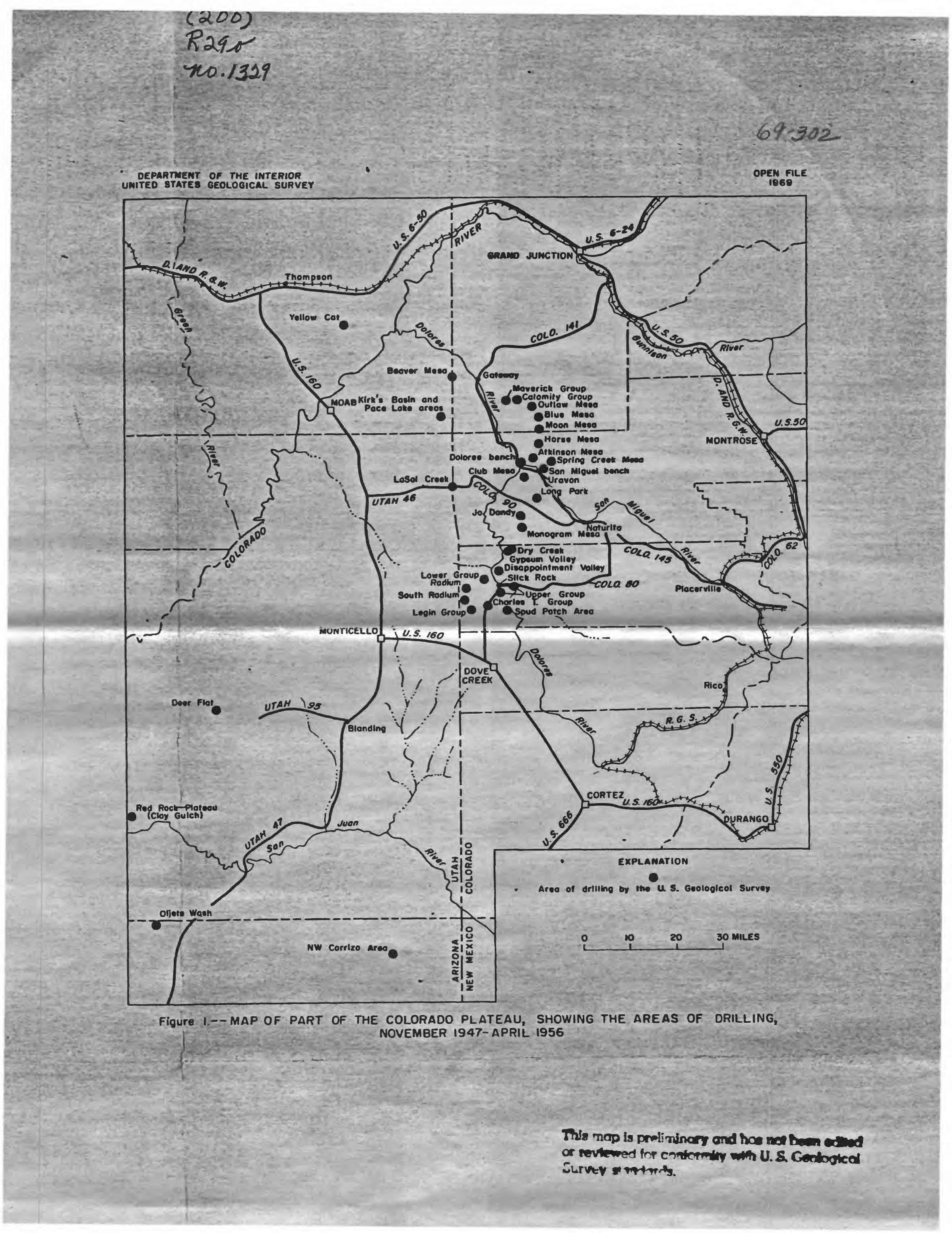




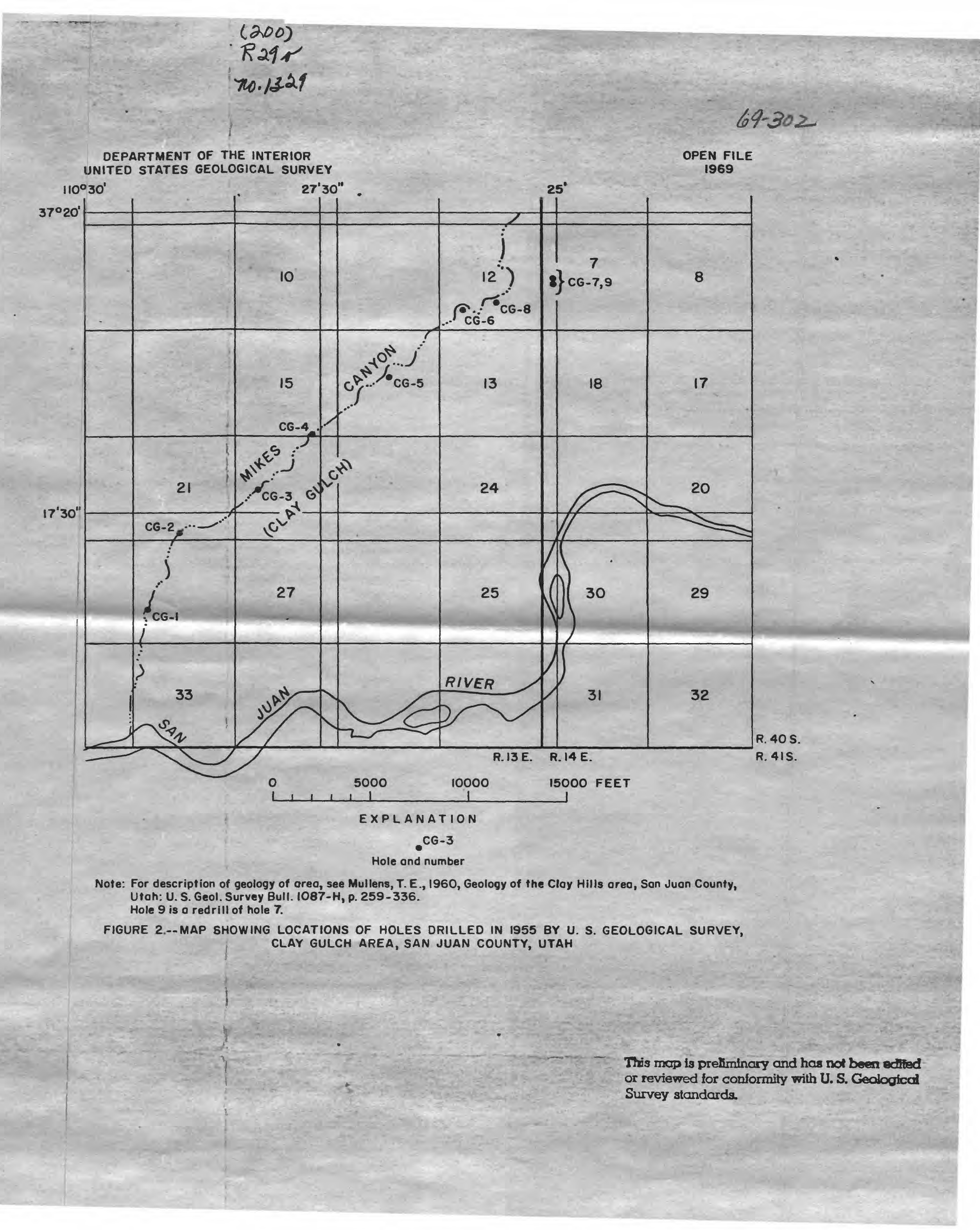

